\title{
Uso de Produto à Base de Enzima e Levedura na Dieta de Bovinos: Digestibilidade dos Nutrientes e Desempenho em Confinamento 1
}

\section{Ralf Cezar de Queiroz², Antônio Fernando Bergamaschine ${ }^{3}$, João Francisco Pereira Bastos ${ }^{3}$, Pedro César dos Santos ${ }^{4}$, Guilherme Corbucci Lemos ${ }^{5}$}

\begin{abstract}
RESUMO - Objetivou-se, com este trabalho, avaliar os efeitos da adição de diferentes níveis de enzima mais levedura na dieta de bovinos sobre a digestibilidade aparente dos nutrientes e o desempenho em confinamento, utilizando-se 18 animais machos, mestiços,

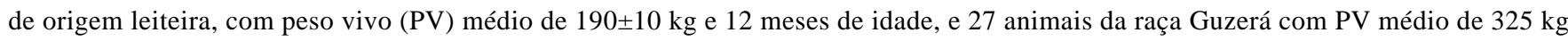
e idade média de 27 meses. Os níveis de enzima mais levedura foram zero (controle), $5 \mathrm{~g}$ de enzima (E) mais $5 \mathrm{~g}$ de levedura (L) e $10 \mathrm{~g}$ de E mais $5 \mathrm{~g}$ de L por animal por dia. Todos os animais receberam a mesma dieta, constituída de 65\% de silagem (50\% de milho:50\% de sorgo) e $35 \%$ de concentrado composto de milho (24,6\%), farelo de algodão (7,4\%), uréia (1,2\%), sal mineralizado $(0,54 \%)$ e calcário $(0,86 \%)$. Esta dieta apresentava 12,4\% de PB; 10,1 MJEM/kg MS e 41,1\% de FDN. A adição de enzima mais levedura não alterou o consumo de MS (3,31\% do PV ou 126,6 g/kg PV $\left.{ }^{0,75}\right)$, e CDA da MS (63,0\%), PB (68,2\%), EE (83,3\%), CHOT (61,3\%), FDN (47,2\%), FDA $(43,8 \%)$ e valor de NDT $(62,8 \%)$. O GMD e o CMS diminuíram de forma quadrática e a CA alimentar piorou linearmente, em função dos dias de confinamento. O fornecimento de enzima mais levedura para bovinos de corte não traz benefícios nutricionais ou de desempenho.
\end{abstract}

Palavras-chave: aditivo, ruminante, Saccharomyces cerevisiae, xilanase

\section{Use of Product from Enzyme and Yeast in the Cattle Diet: Nutrients Digestibility and Performance in Feedlot}

\begin{abstract}
The objetive of this work was to evaluate the effect of the addition of different enzyme levels plus yeast in the cattle diet on apparent nutrient digestibility and cattle performance in feedlot. Is was used 18 crossbred bulls (Taurino x Zebuino) of milk dairy origin with average LW of $190 \pm 10 \mathrm{~kg}$ and age of 12 months and 27 steer of the Guzerá breed with LW and age of $325 \mathrm{~kg}$ and 27 months. The levels of enzyme plus yeast were zero (control), $5 \mathrm{~g}$ of enzyme (E) plus $5 \mathrm{~g}$ of yeast (Y) and $10 \mathrm{~g}$ E plus $5 \mathrm{~g}$ Y for animal day. All animals received the identical diet with $65 \%$ silage (50\% corn:50\% sorghum) and 35\% of concentrate composed of corn (24.6\%), cottonseed meal (7.4\%), urea (1.2\%), mineralized salt (.54\%) and limestone (.86\%). This diet showed 12.4\% CP, 10.1 MJ ME/kg DM and $41.1 \%$ NDF. The enzyme plus yeast did not affected DM intake (3.3\% LW or $126.6 \mathrm{~g} / \mathrm{kg} \mathrm{LW}^{.75}$ ) and ACD of DM (63.3\%), CP (68.2\%), EE (83.3\%), TCHO (61.3\%), NDF (47.2\%), ADF (43.8\%), and TDN value (62.8\%). The ADG and DMI decreased of quadratic form and feed:gain ratio worsed linearly, in function of feedlot days. The feeding of enzyme plus yeast for beef cattle did not bring nutritional and performance benefits.
\end{abstract}

Key Words: additive, ruminant, xylanase, Saccharomyces cerevisiae

\section{Introdução}

Nos últimos anos, pesquisas têm mostrado que o uso de enzimas na alimentação de monogástricos, principalmente aves, melhora o valor nutritivo da dieta e, no caso de forragens ensiladas, pode melhorar a fermentação dentro do silo. Estudos mais recentes revisados por Medeiros \& Lanna (1999) mostram que o uso de enzimas exógenas na dieta de ruminantes pode proporcionar melhora na digestibilidade e no desempenho. As enzimas, principalmente celulases e xilanases, são obtidas de extratos da fermentação de bactérias e fungos. Essas enzimas devem atuar conjuntamente com aquelas produzidas pela flora ruminal, no sentido de aumentar a degradação ruminal de forragens.

\footnotetext{
${ }_{1}$ Parte da Dissertação de Mestrado do primeiro autor apresentada ao Programa de Pós-Graduação em Zootecnia - FE/UNESP. ${ }^{2}$ Médico Veterinário, aluno do Programa de Pós-Graduação em Zootecnia - FE/UNESP. Avenida Brasil, 56 - Centro - C.P. 31 CEP: $15385-000$ - Ilha Solteira, SP.

3 Professor do Departamento de Biologia e Zootecnia da FE/UNESP (berga@fio.feis.unesp.br).

${ }^{4}$ Professor do Departamento de Fitotecnia, Tecnologia de Alimentos e Sócio-Economia da FE/UNESP.

${ }^{5}$ Aluno do curso de Agronomia da FE/UNESP.
} 
As leveduras, principalmente Saccharomyces cerevisiae, têm sido usadas na alimentação animal há várias décadas e são consideradas fonte de proteínas de alta qualidade, de vitaminas do complexo B e minerais, especialmente selênio e zinco.

O uso de leveduras na alimentação de ruminantes também tem sido cogitado em pequena quantidade, como aditivo, consistindo em fator de crescimento para bactérias do rúmen, principalmente celulolíticas.

Segundo Wallace (1994), o uso de culturas dos fungos Saccharomyces cerevisiae e Aspergillus oryzae, ou seus extratos, pode melhorar o ganho de peso e a produção de leite com intensidade semelhante aos ionóforos $(7,0 \%-8,0 \%)$, decorrentes da resposta ao aumento na ingestão de matéria seca. E ainda, as respostas são variáveis e dependentes da quantidade oferecida e do tipo de dieta. Analisando-se as literaturas revisadas por Wallace (1994) e Newbold (2001), constata-se que as leveduras (Saccharomyces cerevisiae) removem o oxigênio que chega ao rúmen através do alimento e da saliva, proporcionando aumento no número de bactérias celulolíticas viáveis, sendo que as bactérias que utilizam ácido lático são estimuladas pela presença de ácidos dicarboxílicos. Assim, o pH do rúmen torna-se mais estável, a metanogênese e a proporção de ácidos graxos voláteis são alteradas e a concentração de ácido lático diminui. Essas mudanças elevam a taxa de digestão da celulose e o fluxo de proteína microbiana, o que resulta em maior ingestão de matéria seca e, portanto, melhor desempenho.

A relação volumoso:concentrado da dieta também parece determinar o efeito das leveduras. Carro et al. (1992), trabalhando com equipamento Rusitec e diferentes níveis de concentrado, observaram que os efeitos benéficos da adição de leveduras sobre os parâmetros da fermentação e degradação da fibra se manifestaram com o maior nível de concentrado (70\%).

No Estado do Texas (EUA), Greene (2002) coordenou um experimento de confinamento com 669 novilhas pesando, aproximadamente, $316 \mathrm{~kg}$, em que foram testados três níveis de levedura: 0,$0 ; 5,0$ e 20,0 g/animal/dia. Os animais receberam dieta com 97\% de concentrado e foram implantadas com hormônio. O ganho de peso aumentou linearmente: 1,$125 ; 1,184$ e $1,266 \mathrm{~kg} / \mathrm{dia}$, para as respectivas quantidades de levedura. Este aumento eqüivale a 5,3 e 12,4\% para o nível de 5,0 e 20,0 g de levedura em relação aos animais não-suplementados. $O$ consumo de matéria seca $(7,5 ; 7,8$ e 7,6 kg/dia) não variou.
Trabalhando com novilhas Holandês-Zebu (247 kg) e dietas à base de cana-de-açúcar (82 a 88\% da MS), Miranda et al. (1999), ao fornecerem 10,0 g/animal/dia de levedura, obtiveram resposta positiva no consumo de matéria seca, quando comparada à não-suplementação $\left(94,9 \times 85,5 \mathrm{~g} / \mathrm{kgPV}^{0,75}\right)$, e no ganho de peso vivo $(0,67 \times 0,51 \mathrm{~kg} / \mathrm{dia})$.

Alimentando novilhos Simental $(374,0 \mathrm{~kg}) \mathrm{com}$ dietas contendo $49,0 \%$ de feno de Tifton, Miranda et al. (2001) não obtiveram resposta ao fornecimento de 5,0 g/animal/dia de levedura. O ganho de peso e o consumo de MS médios foram de 1,54 kg/dia e 2,14\% do peso vivo. A levedura, porém, promoveu aumento $(6,3 \%)$ no ganho de peso.

Em experimento de digestão e metabolismo, também conduzido por Greene (2002), novilhos foram alimentados com 9,8 kg MS/dia de uma dieta contendo $90,0 \%$ de concentrado e zero ou $0,26 \%$ de levedura na MS. As digestibilidades da MS (79,2 x 77,8\%), proteína bruta $(74,7$ x 75,1\%) e FDA $(42,0$ x 36,3\%) não mostraram diferenças significativas, mas o $\mathrm{pH}$ do rúmen aumentou $(5,8 \times 6,5)$ com a suplementação de levedura. O autor também observou que a levedura melhorou a utilização do cálcio e do fósforo da dieta.

No Brasil, resultados favoráveis ao uso de levedura não foram confirmados por Pereira et al. (2001), em estudo de digestibilidade com novilhos utilizando dietas à base de cana-de-açúcar. O consumo médio de MS foi de $89,1 \mathrm{~g} / \mathrm{kgPV}^{0,75}$ ou $2,13 \%$ do peso vivo. Os coeficientes de digestibilidade médios da MS, PB, EE, FDN e CHOT foram de 49,6; 54,3; 71,0; 31,6 ; e $50,9 \%$, respectivamente. Os autores concluíram que o uso de leveduras não influencia o consumo e a digestibilidade.

Os produtos comerciais à base de enzimas são extratos da fermentação de bactérias (Bacillus sp.) ou fungos (Trichoderma e Aspergillus sp.), que são adicionados em quantidades que variam de 0,01 a $1,00 \%$ da dieta e que podem contribuir com até $15,0 \%$ da atividade fibrolítica total do rúmen (Beauchemin \& Rode, 1996).

A substituição do antibiótico Rumensin-Tylan por um coquetel de enzimas extraídas de bactérias, fungos e leveduras, na dieta de bovinos na fase de terminação, foi realizada por Weichenthal et al. (1996), com dieta contendo $88,0 \%$ de concentrado. O ganho diário e a conversão alimentar foram favoráveis ao uso de enzimas em 10,0 e 7,5\%, respectivamente, sem alteração no consumo de MS. Portanto, o uso de enzimas pode ser ainda mais efetivo que o de antibióticos.

\section{R. Bras. Zootec., v.33, n.6, p.1548-1556, 2004}


Zheng et al. (1996), trabalhando com novilhas, alimentadas com silagem de capim e $10,0 \%$ de concentrado, não obtiveram respostas ao fornecimento de enzimas (celulase + xilanase) sobre o consumo de MS e ganho de peso. Entretanto, Pritchard et al. (1996) observaram aumento no consumo de MS, no ganho de peso e na eficiência alimentar em resposta a níveis crescentes de fornecimento de enzimas (celulase + xilanase) para novilhos recebendo $30,0 \%$ de concentrado.

De modo geral, observa-se que as respostas ao fornecimento de enzimas são pequenas e inconsistentes, conforme foi observado por Beauchemin \& Rode (1996). Esses autores sugeriram que a inconsistência dos resultados decorre de diversos fatores - composição da dieta, tipo de enzima, atividade do complemento da enzima, quantidade de enzima fornecida, estabilidade da enzima e método de aplicação.

Os resultados de pesquisas sobre os efeitos do uso de enzimas ou leveduras na dieta sobre o desempenho animal são variáveis, e resultados do uso concomitante de enzimas e leveduras são escassos ou inexistentes. Efeitos adicionais do uso em conjunto de enzima mais levedura, na utilização dos alimentos, poderiam proporcionar respostas mais consistentes no desempenho de bovinos.

Objetivou-se, com este estudo, avaliar os efeitos da adição de enzima (xilanase) em conjunto com levedura sobre o consumo e a digestibilidade dos nutrientes e desempenho de bovinos confinados.

\section{Material e Métodos}

O trabalho foi realizado na Fazenda de Ensino e Pesquisa da Faculdade de Engenharia de Ilha Solteira, em Ilha Solteira - SP, no período de agosto a novembro de 2002. Foram realizados dois experimentos: um para determinar o consumo e a digestibilidade dos nutrientes e outro para avaliar o desempenho de bovinos em confinamento. Os tratamentos consistiram da adição de levedura e enzima: $\mathrm{T}_{1}$ - testemunha (sem adição); $\mathrm{T}_{2}-5,0 \mathrm{~g}$ de enzima $+5,0 \mathrm{~g}$ de levedura/animal/dia; $\mathrm{T}_{3}-10,0 \mathrm{~g}$ de enzimas $+5,0 \mathrm{~g}$ de levedura/animal/dia. As quantidades totais diárias ( 10,0 ou $15,0 \mathrm{~g}$ ) foram diluídas em $100 \mathrm{~g}$ do concentrado e fornecidas em duas porções diárias (8 e 16h), adicionadas sobre a silagem, no cocho. Estas foram adicionadas sobre a silagem, no cocho e, só após o consumo, era fornecido o concentrado misturadoà silagem.
A dieta, em ambos os experimentos, foi ajustada conforme recomendações do AFRC (1993). Considerou-se o consumo de matéria seca como 3,0 e 2,5\% do peso vivo, para os animais dos ensaios de digestibilidade e de desempenho, respectivamente, em função dos pesos, das idades e condições corporais. A relação volumoso:concentrado foi de 65:35 e o ganho de peso esperado, de $1,1 \mathrm{~kg} / \mathrm{dia}$. O volumoso utilizado foi silagens de milho e de sorgo, misturadas na relação de 50:50 (base natural). A dieta era constituída de $65,4 \%$ de silagem, $24,6 \%$ de milho moído, 7,4\% de farelo de algodão, $1,2 \%$ de uréia, $0,54 \%$ de sal mineralizado $(1: 1)$ e $0,86 \%$ de calcário calcítico, em base seca. Aos 60 dias do confinamento, o concentrado foi acrescido com $20 \%$ de milho moído. A composição bromatológica dos ingredientes e da dieta está apresentada na Tabela 1.

No experimento de digestibilidade, foram utilizados 18 bezerros cruzados (Taurino x Zebuíno) de origem leiteira, sem grau de sangue definido, com peso vivo e desvio-padrão médios de $190 \pm 10 \mathrm{~kg}$ e idade aproximada de 12 meses. Esses animais foram previamente vacinados contra febre aftosa e carbúnculo sintomático, e tratados contra ecto e endoparasitos. Inicialmente, foram submetidos ao confinamento, em baias individuais $(2,5 \times 5,0 \mathrm{~m})$, e alimentados com silagem de sorgo, concentrado e sal mineral, por 15 dias. Em seguida, foram pesados e distribuídos, conforme seus pesos, em três lotes referentes aos três tratamentos. Durante 15 dias, a dieta foi oferecida à vontade duas vezes ao dia (8 e 16h) e o consumo, medido nos últimos cinco dias.

O período de coleta foi de seis dias, precedidos de dois dias de adaptação às gaiolas de estudos de digestibilidade. Neste período, o consumo foi controlado de modo que as sobras fossem mínimas. As fezes foram coletadas duas vezes ao dia, antes da alimentação. Após pesagem e homogeneização, alíquotas de 5,0\% foram embaladas em sacos plásticos e congeladas a $-10^{\circ} \mathrm{C}$. Eventuais sobras de alimentos foram pesadas e homogeneizadas, tomando-se alíquotas de aproximadamente $200 \mathrm{~g}$ por animal, que foram congeladas. No final do período de coleta, amostras de fezes e de sobras de alimentos foram compostas, obtendo-se uma amostra média de fezes e de sobras de alimentos por animal. As silagens e a ração concentrada foram amostradas duas vezes por semana. As fezes, as sobras e os alimentos foram analisados para determinação dos teores de matéria seca (MS), proteína bruta (PB), extrato etéreo (EE),

\section{R. Bras. Zootec., v.33, n.6, p.1548-1556, 2004}


matéria mineral (MM), fibra detergente neutro (FDN) e fibra detergente ácido (FDA), conforme metodologia descrita por Silva (1981). Os valores dos nutrientes digestíveis totais (NDT) e carboidratos totais (CHOT) foram obtidos segundo Sniffen et al. (1992).

No experimento de desempenho, foram utilizados 27 animais machos, castrados, da raça Guzerá com peso vivo entre 300 e $350 \mathrm{~kg}$ e idade variando de 24 a 30 meses. Os animais foram confinados em baias individuais de 2,5 x 5,0 m, concretadas, com cochos individuais e bebedouro comum a cada duas baias. Os tratamentos, a dieta e o fornecimento foram semelhantes aos do ensaio de digestibilidade. As sobras de ração foram controladas cinco vezes por semana e amostradas duas vezes por semana, para controle do consumo.

Os animais foram pesados no início do experimento e a cada 28 dias, sem a alimentação da tarde do dia anterior, portanto, um jejum aproximado de 16 horas. A pesagem dos animais foi realizada a partir das 7 h30. A coleta de dados teve duração de 112 dias (quatro períodos de 28 dias) precedidos de 20 dias de adaptação. Silagem (mistura) e alimentos concentrados foram amostrados uma vez por semana.
O delineamento em blocos ao acaso foi adotado em ambos experimentos; no de desempenho, foram utilizadas nove repetições e o período (tempo) foi analisado como subparcela, estabelecendo-se regressão entre os dias de confinamento (períodos de 28 dias). No estudo de digestibilidade, foram adotadas seis repetições por tratamento. Foram feitas análise de variância e comparação das médias pelo teste Tukey, a 5\% de probabilidade.

\section{Resultados e Discussão}

Os dados referentes ao consumo de matéria seca (CMS) em porcentagem do peso vivo (kgMS/100kgPV) e em relação ao peso metabólico $\left(\mathrm{gMS} / \mathrm{kgPV}^{0,75}\right)$, bem como os coeficientes de digestibilidade aparente da matéria seca (MS), proteína bruta (PB), extrato etéreo (EE), carboidratos totais (CHOT), fibra em detergente neutro (FDN), fibra em detergente ácido (FDA) e nutrientes digestíveis totais (NDT) são apresentados na Tabela 2 .

$\mathrm{A}$ adição de enzima e levedura $(\mathrm{E}+\mathrm{L})$ e a quantidade de enzima ( 5 ou $10 \mathrm{~g} /$ dia) não afetaram (P>0,05) o CMS. Entretanto, houve aumento de 8,7\%

Tabela 1 - Composição bromatológica dos ingredientes e da dieta

Table1 - Chemical composition of the ingredients and diet

\begin{tabular}{|c|c|c|c|c|c|}
\hline $\begin{array}{l}\% \mathrm{MS} \\
D M \%\end{array}$ & $\begin{array}{l}\text { Silagem } \\
\text { Silage }\end{array}$ & $\begin{array}{l}\text { Milho moído } \\
\text { Ground corn }\end{array}$ & $\begin{array}{l}\text { Farelo algodão } \\
\text { Cottonsed meal }\end{array}$ & $\begin{array}{l}\text { Uréia } \\
\text { Urea }\end{array}$ & $\begin{array}{c}\text { Dieta }^{1} \\
\text { Diet }^{1}\end{array}$ \\
\hline MS & 35,0 & 89,8 & 90,5 & 98,1 & 54,3 \\
\hline $\begin{array}{l}\mathrm{PB} \\
C P\end{array}$ & 6,2 & 7,8 & 43,5 & $274,5^{5}$ & 12,4 \\
\hline $\begin{array}{l}\mathrm{EM}^{2,3} \\
M E^{2,3}\end{array}$ & 9,2 & 13,3 & 11,0 & - & 10,1 \\
\hline $\begin{array}{l}\mathrm{MM} \\
M M\end{array}$ & 8,0 & 1,5 & 6,5 & - & 6,1 \\
\hline $\begin{array}{l}\mathrm{EE} \\
E E\end{array}$ & 2,7 & 4,8 & 0,9 & - & 3,0 \\
\hline$\underset{T C}{\mathrm{CHOT}^{4}}$ & 83,1 & 85,9 & 49,1 & - & 79,1 \\
\hline $\begin{array}{l}\text { FDN } \\
N D F\end{array}$ & 54,5 & 14,8 & 24,9 & - & 41,1 \\
\hline $\begin{array}{l}\text { FDA } \\
A D F\end{array}$ & 38,7 & 5,4 & 17,5 & - & 27,9 \\
\hline
\end{tabular}

${ }^{1}$ Estimada(Estimated).

${ }^{2}$ NRC (1996).

${ }^{3} \mathrm{Mcal} \times 4,184=\mathrm{MJ} / \mathrm{kgMS}($ Mcal x $4.184=\mathrm{MJ} / \mathrm{kgDM})$.

${ }^{4}$ Estimado segundo Sniffen et al. (1992) (Estimated of according to Sniffen et al. [1992]).

5 Equivalente protéico (Equivalent protein). 
no CMS (g MS/kg PV ${ }^{0,75}$ ), com a adição de $10+5$ g/ animal/dia de $\mathrm{E}+\mathrm{L}$, em relação ao controle, e de $4,8 \%$, em relação ao fornecimento de $5+5 \mathrm{~g}$ de $\mathrm{E}+\mathrm{L}$, o qual aumentou o consumo em $3,6 \%$ em relação à dieta controle (sem E + L). Aumento semelhante no CMS (9,7\%) foi observado por Caton et al. (1993), ao fornecerem enzimas para bovinos de corte a pasto. De modo geral, o consumo foi elevado e reflete a fase de crescimento dos animais (192 kg e 12 meses de idade). Ausência de resposta significativa no CMS relacionada à adição de enzima, em dietas de bovinos de corte, também foi observada por Lewis et al. (1996) e Krause et al. (1998). Beauchemin et al. (1995) verificaram que o consumo de matéria seca variou com o nível de enzima, o tipo de volumoso (feno ou silagem) e a espécie (gramínea ou leguminosa).

Greene (2002) observou aumento de apenas 4,3\% no CMS, em resposta ao fornecimento de $0,26 \%$ de levedura (Biosaf) na dieta de novilhos. Pereira et al. (2001) não encontraram efeito inerente ao fornecimento de $10 \mathrm{~g} / \mathrm{dia}$ de leveduras para novilhos recebendo dietas à base de cana-de-açúcar.

Os coeficientes de digestibilidade aparente da MS e os teores de NDT não apresentaram diferenças (P>0,05), em função da adição de $\mathrm{E}+\mathrm{L}$ e do nível de enzima 5,0 ou $10,0 \mathrm{~g} / \mathrm{dia}$. Todavia, a digestibilidade de PB diminuiu (3,3\%) e a de EE, CHOT, FDN e FDA apresentaram aumentos médios de 5,0; 8,2; 7,0 e $11,0 \%$, respectivamente, com a adição de $\mathrm{E}+\mathrm{L}$. Entretanto, as diferenças não foram significativas e refletem a ausência de resposta nos teores de NDT das dietas. Estes resultados corroboram os obtidos por Lewis et al. (1996), que observaram melhora inferior a 5,0\% na digestibilidade da MS $(63,8 \%)$, FDN $(59,0 \%)$ e FDA $(57,0 \%)$, quando forneceram enzimas a novilhos recebendo dieta com $70 \%$ de volumoso. Ao contrário, Krause et al. (1998), obtiveram aumento significativo digestibilidade da FDA, de dietas de novilhos contendo palha ou silagem de cevada e $90,0 \%$ de concentrado, quando

Tabela 2 - Consumo de matéria seca (CMS) e coeficiente de digestibilidade aparente (CDA) dos nutrientes de dietas adicionadas com diferentes níveis de enzima e levedura

Table 2 - Dry matter intake (DMI) and coefficient of apparent digestibility (CAD) of the dietary nutrients with different levels of enzyme and yeast

\begin{tabular}{|c|c|c|c|c|}
\hline \multirow[t]{2}{*}{$\begin{array}{l}\text { Parâmetros } \\
\text { Parameters }\end{array}$} & \multicolumn{3}{|c|}{$\begin{array}{l}\text { Níveis de enzima mais levedura (g/dia) } \\
\text { Levels of enzyme plus yeast (g/day) }\end{array}$} & \multirow[b]{2}{*}{$\mathrm{CV}(\%)$} \\
\hline & 0 & $5+5$ & $10+5$ & \\
\hline \multicolumn{5}{|l|}{ CMS } \\
\hline$D M I$ & & & & \\
\hline $\mathrm{kgMS} / 100 \mathrm{~kg} P \mathrm{P}$ & 3,16 & 3,37 & 3,42 & 7,02 \\
\hline $\begin{array}{l}\mathrm{kgDM} / 100 \mathrm{~kg} \mathrm{LW} \\
\mathrm{gMS} / \mathrm{kg} \mathrm{PV}^{0,75} \\
\mathrm{gDM} / \mathrm{kgLW}^{.75}\end{array}$ & 121,54 & 126,00 & 132,17 & 7,12 \\
\hline \multicolumn{5}{|l|}{$\mathrm{CDA}(\%)$} \\
\hline $\begin{array}{l}\text { MS } \\
D M\end{array}$ & 63,01 & 63,68 & 62,36 & 3,88 \\
\hline $\begin{array}{l}\mathrm{PB} \\
C P\end{array}$ & 69,39 & 68,15 & 67,15 & 4,59 \\
\hline $\begin{array}{l}\mathrm{EE} \\
E E\end{array}$ & 80,59 & 84,85 & 84,37 & 4,66 \\
\hline $\begin{array}{l}\text { CHOT } \\
T C\end{array}$ & 58,09 & 63,39 & 62,38 & 13,40 \\
\hline $\begin{array}{l}\text { FDN } \\
N D F\end{array}$ & 45,07 & 48,62 & 47,81 & 9,68 \\
\hline $\begin{array}{l}\text { FDA } \\
A D F\end{array}$ & 40,87 & 45,64 & 45,09 & 9,45 \\
\hline $\begin{array}{l}\text { NDT } \\
T D N\end{array}$ & 62,99 & 62,71 & 62,89 & 3,76 \\
\hline
\end{tabular}

NDT conforme Sniffen et al. (1992).

$T D N$ according to Sniffen et al. (1992).

$(P>0,05)$.

R. Bras. Zootec., v.33, n.6, p.1548-1556, 2004 
forneceram enzimas celulases e xilanases. Resultados semelhantes foram obtidos por Beauchemin et al. (1995), porém houve interação entre tipo e espécie de forragem e nível de enzimas. Judkins \& Stobart (1988) observaram aumento significativo na digestibilidade da parede celular com a suplementação de $35 \mathrm{~g} / \mathrm{dia}$ de enzimas na dieta, com $10 \%$ de milho, para ovinos, em relação ao controle e $22 \mathrm{~g}$ /dia de enzimas. Quando a dieta apresentou 25,0\% de milho, não houve diferença significativa. Resultados semelhantes foram obtidos por Yang et al. (1999), quando suplementaram $20 \mathrm{~g} / \mathrm{dia}$ de enzimas para vacas de leite, mas não houve diferença na digestibilidade da fibra (FDN e FDA), com $10 \mathrm{~g} /$ dia de enzimas. No entanto, Rode et al. (1999) forneceram quantidade semelhante $(23 \mathrm{~g} / \mathrm{dia})$ de enzimas para vacas e obtiveram aumento significativo na digestibilidade da MS, PB, FDN e FDA, comprovando que a resposta ao fornecimento de enzimas depende da quantidade fornecida.

Chademana \& Offer (1990), trabalhando com ovinos, e Pereira et al. (2001), com novilhas, não verificaram efeito sobre a digestibilidade dos nutrientes, com adição de leveduras na dieta.

Wiedmeier et al. (1987) forneceram 90,0 g de levedura ou de extrato da fermentação de Aspergillus oryzae (AO), ou uma mistura de ambos (90 g de levedura e 2,6 $\mathrm{g}$ de $\mathrm{AO}$ ), para vacas secas recebendo dieta com $50,0 \%$ de concentrado, e observaram aumento significativo na digestibilidade da MS, PB e hemicelulose. A adição de enzima ou somente levedura também aumentou a digestibilidade, mas não houve diferença entre os dois aditivos. O número de bactérias celulolíticas também aumentou com o fornecimento de aditivos. Os autores ressaltaram que a combinação de Aspergillus oryzae, que produz enzimas celulases, com leveduras, que fornecem fatores estimuladores para as bactérias celulolíticas, foi mais benéfico que o fornecimento isolado desses aditivos. Entretanto, é importante salientar que as condições experimentais eram distintas das do presente trabalho, principalmente com relação às quantidades de aditivos fornecidas.

Na Tabela 3, são apresentados os parâmetros avaliados no confinamento que foram ganho de peso vivo médio diário ( $\mathrm{kg} / \mathrm{dia})$, consumo de matéria seca em quilos por dia ( $\mathrm{kg} / \mathrm{dia})$, em porcentagem do peso vivo (\%PV), em gramas de matéria seca por quilo de peso metabólico (gMS/kgPV ${ }^{0,75}$ ) e conversão alimentar em quilo de matéria seca consumida por quilo de ganho de peso vivo (kgMS/kgGPV).

O ganho médio diário (GMD) e o consumo de matéria seca (CMS) apresentaram acréscimo médio de 5,2 e $4,0 \%$, respectivamente, em resposta ao fornecimento de $\mathrm{E}+\mathrm{L}(5+5$ ou $10+5 \mathrm{~g} / \mathrm{dia})$, entretanto, as diferenças não foram significativas $(\mathrm{P}>0,05)$. Estes resultados concordam parcialmente com aqueles obtidos por Mutsvangwa et al. (1992), que forneceram $10 \mathrm{~g} / \mathrm{animal} / \mathrm{dia}$ de levedura para bezerros, observando aumento no CMS, mas não no GMD. Tal fato foi atribuído ao aumento na taxa de fermentação ruminal, sem alterar a natureza da fermentação. Além disso, os autores justificaram que o rápido crescimento dos animais que não receberam levedura e o alto teor de proteína bruta da dieta podem não ter permitido melhora no ganho de peso, em resposta ao maior CMS.

Tabela 3 - Ganho médio diário (GMD), consumo de matéria seca (CMS) e conversão alimentar (CA) de novilhos suplementados com diferentes níveis de enzima mais levedura

Table 3 - Average daily gain (ADG), dry matter intake (DMI) and feed:gain ratio (F:G) of young bulls supplemented with different levels of enzyme plus yeast

\begin{tabular}{|c|c|c|c|c|c|}
\hline Níveis & GMD & & CMS & & CA \\
\hline $\begin{array}{l}\text { Levels } \\
\text { (g/dia) }\end{array}$ & $D A G$ & & $D M I$ & & $F: G$ \\
\hline Enzima + & $\mathrm{kg} / \mathrm{dia}$ & $\mathrm{kg} / \mathrm{dia}$ & $\% \mathrm{PV}$ & $\mathrm{g} / \mathrm{kgPV}^{0,75}$ & $\mathrm{kgMS} / \mathrm{kgGPV}$ \\
\hline $\begin{array}{l}\text { Enzyme + } \\
\text { Levedura }\end{array}$ & $\mathrm{kg} /$ day & $\mathrm{kg} /$ day & $\% L W$ & $g / k g L W^{0.75}$ & $\mathrm{kgDM} / \mathrm{kgLWG}$ \\
\hline \multicolumn{6}{|l|}{ Yeast } \\
\hline 0 & 0,884 & 8,79 & 2,42 & 106,22 & 10,71 \\
\hline $5+5$ & 0,925 & 9,32 & 2,50 & 110,15 & 10,44 \\
\hline $10+5$ & 0,935 & 9,34 & 2,52 & 110,74 & 10,73 \\
\hline $\mathrm{CV}$ & 37,97 & 16,00 & 12,79 & 13,21 & 21,68 \\
\hline
\end{tabular}

R. Bras. Zootec., v.33, n.6, p.1548-1556, 2004 
Mir \& Mir (1994), trabalhando com dieta mais volumosa (silagem de alfafa) ou mais concentrada (cevada), também não observaram diferenças nos parâmetros de desempenho, ao fornecerem $10 \mathrm{~g} / \mathrm{animal} / \mathrm{dia}$ de levedura para novilhos. No entanto, com dieta volumosa, à base de silagem de milho, o CMS aumentou, sem afetar o ganho, e, portanto, a conversão piorou. Entre dez trabalhos analisados por Zinn \& Shen (1994), em apenas dois foi observado aumento no ganho de peso, quando se adicionou levedura na dieta.

$\mathrm{O}$ fornecimento de $10 \mathrm{~g} / \mathrm{animal} / \mathrm{dia}$ de levedura para novilhas recebendo dietas à base de cana-deaçúcar favoreceu significativamente o ganho de peso e o consumo de MS, porém não afetou a conversão (Miranda et al., 1999). Também com novilhas, mas fornecendo dietas com alta proporção de concentrado, Greene (2002) observou maior ganho de peso, quando suplementou 5,0 ou $20 \mathrm{~g} / \mathrm{animal} / \mathrm{dia}$ de levedura. A diferença entre o testemunha e o tratamento com $5,0 \mathrm{~g} / \mathrm{animal} / \mathrm{dia}$ de levedura foi de $5,2 \%$, portanto, idêntica à do presente trabalho.

A quantidade fornecida de enzima ( 5 ou $10 \mathrm{~g} / \mathrm{dia}$ ) não afetou $(\mathrm{P}>0,05)$ os parâmetros de desempenho. Aparentemente, o fornecimento de enzima melhorou o GMD e o CMS em 5,2 e 4,0\%, respectivamente, resultado que pode, também, estar relacionado ao fornecimento de levedura conjuntamente. Michal et al. (1996) forneceram celulose + xilanase e observaram aumento maior $(8,7 \%)$ no CMS, mas o ganho e a conversão não foram afetados. Weichenthal et al. (1996) observaram que o fornecimento de $0,1 \%$, na matéria seca da ração $(10,0-11,0 \mathrm{~g} / \mathrm{animal} / \mathrm{dia})$ de um coquetel de enzimas e microrganismos (bactérias, leveduras e fungos) melhorou o ganho de peso em $10,0 \%$ e a conversão alimentar em $7,5 \%$, em relação ao fornecimento de Rumensin-Tylan como aditivo. Pritchard et al. (1996) observaram aumento no GMD,

Tabela 4 - Média e regressão do ganho médio diário (GMD), consumo de matéria seca (CMS) e conversão alimentar (CA) de novilhos suplementados com diferentes níveis de enzima mais levedura, em função dos dias de confinamento (períodos de 28 dias)

Table 4 - Mean and regression of weight daily gain (WDG), dry matter intake (DMI) and feed: gain ratio (F:G) of young bulls suplemented with different levels of enzyme plus yeast

\begin{tabular}{|c|c|c|c|c|c|c|}
\hline \multirow[t]{2}{*}{$\begin{array}{l}\text { Parâmetros } \\
\text { Parameters }\end{array}$} & & \multicolumn{4}{|c|}{$\begin{array}{l}\text { Período de confinamento } \\
\text { Period offeedlot }\end{array}$} & \multirow[b]{2}{*}{$\mathrm{CV}(\%)$} \\
\hline & & $1 \underline{0}$ & $2^{\underline{o}}$ & 39 & $4-$ & \\
\hline $\begin{array}{l}\text { GMD } \\
D A G\end{array}$ & $\begin{array}{l}\mathrm{kg} / \mathrm{dia} \\
\mathrm{kg} / \text { day }\end{array}$ & 1,109 & 0,958 & 0,830 & 0,761 & 14,61 \\
\hline \multirow[t]{3}{*}{$\begin{array}{l}\text { CMS } \\
I D M\end{array}$} & $\begin{array}{l}\mathrm{kg} / \mathrm{dia} \\
\mathrm{kg} / \text { day }\end{array}$ & 8,72 & 9,41 & 9,52 & 9,18 & 4,48 \\
\hline & $\begin{array}{l}\% \mathrm{PV} \\
\% L W\end{array}$ & 2,62 & 2,60 & 2,46 & 2,24 & 4,56 \\
\hline & $\begin{array}{c}\mathrm{g} / \mathrm{kg} \mathrm{PV}^{0,75} \\
\mathrm{~g} / \mathrm{kg} \mathrm{LW}^{.75}\end{array}$ & 112,06 & 113,68 & 109,35 & 101,04 & 4,49 \\
\hline $\begin{array}{l}\text { CA } \\
F: G\end{array}$ & $\begin{array}{l}\mathrm{kgMS} / \mathrm{kgGPV} \\
\mathrm{kgDM} / \mathrm{kgLWG}\end{array}$ & 8,10 & 10,04 & 11,78 & 12,60 & 19,89 \\
\hline $\begin{array}{l}\text { GMD } \\
D A G\end{array}$ & $\begin{array}{l}\mathrm{kg} / \mathrm{dia} \\
\mathrm{kg} / \text { day }\end{array}$ & \multicolumn{5}{|c|}{$\hat{Y}=1,358-0,273 x+0,0311 x^{2} ; R^{2}=0,9967$} \\
\hline \multirow[t]{3}{*}{$\begin{array}{l}\text { CMS } \\
I D M\end{array}$} & $\begin{array}{l}\mathrm{kg} / \mathrm{dia} \\
\mathrm{kg} / \text { day }\end{array}$ & \multicolumn{5}{|c|}{$\hat{Y}=7,574+1,370 x-0,242 x^{2} ; R^{2}=0,9933$} \\
\hline & $\begin{array}{l}\% \mathrm{PV} \\
\% L W\end{array}$ & \multicolumn{5}{|c|}{$\hat{Y}=2,568+0,104 x-0,046 x^{2} ; R^{2}=0,9945$} \\
\hline & $\begin{array}{c}\mathrm{g} / \mathrm{kg} \mathrm{PV} \mathrm{P}^{0,75} \\
\mathrm{~g} / \mathrm{kg} L W^{.75}\end{array}$ & \multicolumn{5}{|c|}{$\hat{Y}=105,499+9,187 x-2,577 x^{2} ; R^{2}=0,9997$} \\
\hline $\begin{array}{l}\text { CA } \\
F: G\end{array}$ & $\begin{array}{l}\mathrm{kgMS} / \mathrm{kgGPV} \\
\mathrm{kgDM} / \mathrm{kg} L W G\end{array}$ & \multicolumn{5}{|c|}{$\hat{\mathrm{Y}}=6,695+1,610 \mathrm{x} ; \mathrm{R}^{2}=0,9980$} \\
\hline
\end{tabular}

R. Bras. Zootec., v.33, n.6, p.1548-1556, 2004 
no CMS e na eficiência alimentar. Resultados semelhantes foram obtidos por Beauchemin et al. (1995), que observaram efeito do tipo de forragem (feno ou silagem) e nível de enzima.

A ausência de resposta ao fornecimento de enzima, mesmo que associada com levedura $(5+5 \mathrm{~g}$ ou $10+5 \mathrm{~g})$, pode ser consequência dos baixos níveis utilizados, do tipo de dieta e de outros fatores, como estabilidade da enzima, método de aplicação e atividade do complemento da enzima, conforme Beauchemin \& Rode (1996) quando realizaram ampla revisão sobre este assunto. Zheng et al. (1996) não obtiveram resposta ao fornecimento de enzimas sobre o GMD e CMS.

$\mathrm{O}$ desempenho variou $(\mathrm{P}<0,01)$ em função dos dias de confinamento, que foram representados por quatro períodos de 28 dias. O GMD diminuiu $(\mathrm{P}<0,05)$ e o CMS em $\mathrm{kg} / \mathrm{dia}$ aumentou $(\mathrm{P}<0,01)$ de forma quadrática (Tabela 4). O CMS expresso em relação ao PV (\%PV ou g/kg PV $\left.{ }^{0,75}\right)$ diminuiu $(\mathrm{P}<0,01)$ de maneira quadrática, pois o GMD também reduziu em relação aos dias de confinamento. A CA piorou $(\mathrm{P}<0,01)$ linearmente.

A piora na $\mathrm{CA}$ está mais relacionada à diminuição no ganho de peso que ao aumento no CMS (kg/dia). Esses resultados caracterizam o chamado ganho compensatório. Entretanto, é fato conhecido que o ganho de peso e o consumo, regra geral, diminuem ao longo do tempo, conseqüentemente piora a conversão alimentar. Resultados semelhantes foram obtidos por Santos (1991) e Amaral (1993).

É provável que o ganho compensatório no início do confinamento com ração rica em energia, o aumento da exigência de manutenção e as mudanças na composição do ganho, ocorridas com o ganho de peso, associadas à queda relativa na capacidade de consumo, estejam envolvidas na redução do ganho de peso.

\section{Conclusões}

O fornecimento de enzima (5 ou $10 \mathrm{~g} / \mathrm{animal} / \mathrm{dia}$ ) associada com levedura ( $5 \mathrm{~g} / \mathrm{animal} / \mathrm{dia}$ ) para bovinos não proporciona melhora no consumo e na digestibilidade dos nutrientes. Também não afeta $o$ consumo de alimento, o ganho médio diário e a conversão alimentar de novilhos confinados.

\section{Literatura Citada}

AGRICULTURAL AND FOOD RESEARCH COUNCIL AFRC. Energy and protein requirements of ruminants. Wallingford: CAB International, 1993. 159p.
AMARAL, A.P.F. Avaliação de dois cultivares de milho para silagem - Desempenho de bovinos em confinamento e degradabilidade ruminal. Jaboticabal: Universidade Estadual Paulista, 1993. 56p. Dissertação (Mestrado em Zootecnia) - Universidade Estadual Paulista, 1993.

BEAUCHEMIN, K.A.; RODE, L.M.; SEWALT, V.J.H. Fibrolytic enzymes increase fiber digestibility and growth rate of steers fed dry forages. Canadian Journal of Animal Science, v.75, p.641-644, 1995.

BEAUCHEMIN, K.A.; RODE, L. M. The potential use of feed enzymes for ruminants. In: CORNELL NUTRITION CONFERENCE FOR FEED MANUFACTURERS, 58., 1996. Procedings... Ithaca: Cornell University, 1996. p.131-141.

CARRO, M.D.; LEBZIEN, P.; ROHR, K. Influence of yeast on the "in vitro" fermentation (Rusitec) of diets containing variable portions of concentrates. Animal Feed Science and Technology, v.37, p.209-220, 1992.

CATON, J.S.; ERICKSON, D.O.; CAREY, D.A. et al. Influence of Aspergillus oryzae fermentation extract on forage intake, site of digestion, in situ degradability, andduodenal amino acid flow in steers grazing cool-season pasture. Journal of Animal Science, v.71, p.779-787, 1993.

CHADEMANA, I.; OFFER, N.W. The effect of dietary inclusion of yeast culture on digestion in the sheep. Animal Production, v.50, p.483-489, 1990.

GREENE, W. Use of Saccharomyces cerevisiae in beef cattle. In: SIMPÓSIO GOIANO SOBRE MANEJO E NUTRIÇÃO DE BOVINOS DE CORTE, 4., 2002, Goiânia. Anais... Goiânia: Colégio Brasileiro de Nutrição Animal, 2002. p.79-96.

JUDKINS, M.B.; STOBART, R.H. Influence of two levels of enzyme preparation on ruminal fermentation, particulate and fluid passage and cell wall digestion in wether lambs consuming either a $10 \%$ or $25 \%$ grain diet. Journal of Animal Science, v.66. p.1010-1015, 1988.

KRAUSE, M.; BEAUCHEMIN, K.A.; RODE, L.M. et al. Fibrolytic enzyme treatment of barley grain and source of forage in high-grain diets fed to growing cattle. Journal of Animal Science, v.76, p.2912-2920, 1998.

LEWIS, G.E.; HUNT, C.W.; SANCHEZ, W.K. et al. Effect of direct fed fibrolytic enzymes on the digestive characteristics of a forage-based diet fed to beef steers. Journal Animal Science, v.74, p.3020-3028, 1996.

MEDEIROS, S.R.; LANNA, D.D.P. Uso de aditivos na bovinocultura de corte. In: SIMPÓSIO GOIANO SOBRE PRODUÇÃO DE BOVINOS DE CORTE, 1999, Goiânia. Anais ... Goiânia: Colégio Brasileiro de Nutrição Animal, 1999. p.171-190.

MICHAL, J.J.; JOHNSON, K.A.; TREACHER, R.J. et al. The impact of direct fed fibrolytic enzymes on the growth rate and feed efficiency of growing beef steers and heifers. Journal of Animal Science, v.74, Sup. 1, p.296, Abst. 757, 1996.

MIR, Z.; MIR, P.S. Effect of the addition of live yeast (Saccharomyces cerevisiae) on growth and carcass quality of steers fed high-forage or high-grain diets and on feed digestibility and in situ degradability. Journal of Animal Science, v.72, p.537-545, 1994.

MIRANDA L.F.; CARVALHO, M.A.G.; TAVARES, F.S. et al. Desempenho e características das carcaças de novilhos Simental suplementados com probióticos. In: REUNIÃO ANUAL DA SOCIEDADE BRASILEIRA DE ZOOTECNIA, 38., 2001, Piracicaba. Anais... Piracicaba: Fundação de Estudos Agrários Luiz de Queiroz, 2001. p.1035-1037.

R. Bras. Zootec., v.33, n.6, p.1548-1556, 2004 
MIRANDA, L.F.; QUEIROZ, A.C.; VALADARES FILHO, S.C. et al. Desempenho e desenvolvimento ponderal de novilhas leiteiras alimentadas com dietas à base de canade-açúcar. Revista Brasileira de Zootecnia, v.28, n.3, p.605-613, 1999.

MUTSVANGWA, T.; EDWARDS, I.E.; TOPPS, J.H. et al. The effect of dietary inclusion of yeast culture (Yea - Sacc) on patterns of rumen fermentation, food intake and growth of intensively fed bulls. Animal Production, v.55, p.35-40, 1992.

NEWBOLD, C.J. Proposed mechanisms for enzymes as modifiers of ruminal fermentation. Disponível na Internet. http:// www.animal.ufl.edu/dairy/pubs, capturado em setembro de 2001.

NATIONAL RESARCH COUNCIL - NRC. Nutrient requeriment of beef cattle. 7.ed. Washington, D.C.: National Academy Press, 1996. 242p.

PEREIRA, E.S.; QUEIROZ, A.C.; PAULINO, M.F. et al. Fontes nitrogenadas e uso de Saccharomyces cerevisiae em dietas à base de cana-de-açúcar para novilhos: consumo, digestibilidade, balanço nitrogenado e parâmetros ruminais. Revista Brasileira de Zootecnia, v.30, n.2, p.563-572, 2001.

PRITCHARD, G.; HUNT, C.; ALLEN, A. et al. Effect of direct - fed fibrolytic enzymes on digestion and growth performance in beef cattle. Journal of Animal Science, v.74, Sup. 1, p.296, Abst. 756, 1996.

RODE, L.M.; YANG, W.Z.; BEAUCHEMIN, K.A. Fibrolytic enzyme supplements for dairy cows in early lactation. Journal of Dairy Science, v.82, p.2121-2126, 1999.

SANTOS, F.A.P. Efeito de bicarbonato de sódio, lasolocida e cana-de-açúcar sobre o desempenho de bovinos alimentados com bagaço de cana tratado sob pressão de vapor. Piracicaba: Escola Superior de Agricultura "Luiz de Queiroz". 1991. 127p. Dissertação (Mestrado em Nutrição Animal e Pastagem) - Escola Superior de Agricultura "Luiz de Queiroz", 1991.

SILVA, D.J. Análise de alimentos: métodos químicos e biológicos. Viçosa, MG: Universidade Federal de Viçosa, 1981. 166p.
SNIFFEN, C.J.; O'CONNOR, J.D.; Van SOEST, P.J. et al. A net carbohydrate and protein system for evaluating cattle diets. II. Carbohydrate and protein availability. Journal of Animal Science, v.70, p.3551-3561, 1992.

WALLACE, R.J. Ruminal microbiology, biotechnology, and ruminant nutrition: progress and problems. Journal of Animal Science, v.72, p.2992-3003, 1994.

WEICHENTHAL, A.; RUSH, I.G.; Van PELT, B.G. et al. An enzyme - microbial feed product for finishing steers. Journal of Animal Science, v.74 (Sup. 1), p.84, Abst. 240, 1996.

WIEDMEIER, R.D.; ARAMBEL, M.J.; WALTERS, J.L. Effect of yeast culture and Aspergillus oryzae fermentation extract on ruminal characteristicas and nutrient digestibility. Journal of Dairy Science, v.70, p.2063-2068, 1987.

YANG, W.Z.; BEAUCHEMIN, K.A.; RODE, L.M. Effects of an enzyme feed additive on extent of digestion and milk production of lactating dairy cows. Journal of Dairy Science, v.82, p.391-403, 1999.

ZHENG, S.; STOKES, M.R.; HOMOLA, A. Effects of fibrolytic enzymes on digesta kinects and growth of heifers. Journal of Dairy Science, v.79, Sup. 1, p.235, Abst. 7, 1996.

ZINN, R.A.; SHEN, Y. Probiotics in diets for feedlot cattle. In: SIMPÒSIO LATINO - AMERICANO DE NUTRIÇAO ANIMAL E SEMINÁRIO SOBRE TECNOLOGIA DA PRODUÇÃO DE RAÇÕES, 1994, Campinas. Anais... Campinas: IAC, 1994. p.185-196.

Recebido em: $14 / 08 / 03$

Aceito em: 22/03/04 